\title{
The impact of maternal control on children's anxious cognitions, behaviours and affect: an experimental study
}

Article

Accepted Version

PAPER

Thirlwall, K. J. and Creswell, C. S. (2010) The impact of maternal control on children's anxious cognitions, behaviours and affect: an experimental study. Behaviour Research and Therapy, 48 (19). pp. 1041-1046. ISSN 0005-7967 doi: https://doi.org/10.1016/j.brat.2010.05.030 Available at https://centaur.reading.ac.uk/17281/

It is advisable to refer to the publisher's version if you intend to cite from the work. See Guidance on citing.

To link to this article DOI: http://dx.doi.org/10.1016/j.brat.2010.05.030

Publisher: Elsevier

All outputs in CentAUR are protected by Intellectual Property Rights law, including copyright law. Copyright and IPR is retained by the creators or other copyright holders. Terms and conditions for use of this material are defined in the End User Agreement.

www.reading.ac.uk/centaur 
Central Archive at the University of Reading

Reading's research outputs online 


\section{BEHAVIOUR RESEARCH AND THERAPY, IN PRESS (2010)}

The impact of maternal control on children's anxious cognitions, behaviours and affect: An experimental study.

Kerstin Thirlwall \& Cathy Creswell University of Reading, Berkshire, U.K. RG6 6AL

Corresponding author:

Dr Kerstin Thirlwall

Berkshire Child Anxiety Clinic

Winnicott Research Unit

School of Psychology and Clinical Language Sciences

University of Reading

Reading

Berkshire

UK

RG6 6AL

Email: k.j.thirlwall@ reading.ac.uk

Telephone: 00441183786667

Fax: 00441183786665 


\begin{abstract}
Controlling parenting is associated with child anxiety however the direction of effects remains unclear. The present study implemented a Latin-square experimental design to assess the impact of parental control on children's anxious affect, cognitions and behaviour. A non-clinical sample of 24 mothers of children aged 4-5 years were trained to engage in (a) controlling and (b) autonomy-granting behaviours in interaction with their child during the preparation of a speech. When mothers engaged in controlling parenting behaviours, children made more negative predictions about their performance prior to delivering their speech and reported feeling less happy about the task, and this was moderated by child trait anxiety. In addition, children with higher trait anxiety displayed a significant increase in observed child anxiety in the controlling condition. The pattern of results was maintained when differences in mothers' levels of negativity and habitual levels of control were accounted for. These findings are consistent with theories that suggest that controlling parenting is a risk factor in the development of childhood anxiety.
\end{abstract}

Keywords: Child, anxiety, control, overprotection, parenting 


\section{INTRODUCTION}

Anxiety disorders are one of the most common childhood psychiatric disorders, exceeding both depression and behaviour disorders in their frequency (CartwrightHatton, McNicol \& Doubleday, 2006). The typical age of onset for clinically referred childhood anxiety disorder is between 7 and 12 years (Last, Perrin, Hersen \& Kazdin,1992), however children as young as 21 months have been shown to display behaviours indicative of strong social fears that predict an increased incidence of social phobia in later life (Rosenbaum et al., 1992). Indeed it is likely that the initial acquisition of many fears is early in life (Ohman, 1985). The negative effects of anxiety on children's lives have been well documented (Silverman \& Ginsburg, 1998), yet effective prevention strategies have scope for improvement (Rapee, Kennedy, Ingram, Edwards \& Sweeney, 2005) and theories about the development of anxiety are incomplete. Relatively little is known about why anxiety disorders develop in some children and not others and surprisingly few studies have investigated risk factors that may contribute towards onset in early childhood.

One area which offers a focus for preventative intervention is the role of parenting behaviours. Rapee (2001) has postulated that excessive protection and over-controlling parenting may convey a message to the child that the world is a dangerous place and reduce the child's perception of mastery over novel or threatening events. Furthermore, controlling parenting may minimise the child's experiences of successful independent coping and instead reinforce dependence on others and self doubt. Questionnaire and observational studies have largely supported an association consistent with this theory 
(Wood, McLeod, Sigman, Hwang, \& Chu, 2003; McLeod, Wood \& Weisz, 2006), however few studies have thrown light on the directional nature of the association. In fact Rubin and colleagues (2001) reported that reduced parental control during a structured task was associated with increased inhibited behaviours in preschool children. Inconsistencies may be accounted for, at least in part, by interaction effects, for example it is possible that controlling parenting is more likely to contribute to increased anxiety if the child already has a sensitive temperament (Rapee, 1997). Consistent with this view, Rubin, Burgess and Hastings (2002) reported that the association between toddler inhibition and 4 year old social reticence was significant and positive when mothers demonstrated high frequencies of intrusive control. Similarly, DeRosnay, Cooper, Tsigaras and Murray (2006) showed that the effect of an experimental manipulation of maternal social anxiety was enhanced among young children who were highly inhibited. These studies highlight the possibility that parenting practices moderate the relationship between temperament and later psychological vulnerability.

Whilst naturalistic longitudinal research can provide evidence consistent with causal relationships, it is difficult to account for the possibility that a third variable may explain associations found. For example, particular parenting practices may arise as a function of high parental anxiety, which family aggregation studies have shown is commonly high among parents of highly anxious children (e.g. Cooper, Fearn, Willetts \& Parkinson, 2006). This limitation can be overcome by controlled experimental methodologies. In a recent pilot study, De Wilde and Rapee (2008) manipulated maternal control with 7-13 year old offspring during the preparation of a practice speech. They found that children 
whose mothers engaged in controlling behaviours during the preparation of the practice speech demonstrated greater anxiety when later faced with doing the task alone, compared to children who received minimal control during the practice. This study has shown that it is possible to manipulate parent behaviours and has demonstrated that children can become more anxious following brief single controlling interactions with their parents. A limitation of the study was that instructions to mothers included suggesting mothers give their child a sense of how (in)capable they were of being successful in the task. It was, therefore, unclear whether the effects found were due to differences in maternal control or the provision of negative verbal information (see e.g. Field \& Lawson, 2003) or other potentially overlapping parenting behaviours (e.g. negativity, Hudson \& Rapee, 2001). Furthermore, the children in the study were of an age at which anxiety disorders may already be present (Last et al., 1992) so it remains unclear whether the findings apply to processes in the development of anxiety in younger children.

The present study seeks to build on the findings of De Wilde \& Rapee (2008) by using a Latin-square experimental design to investigate the specific influence of controlling parental behaviours on anxiety in younger children (aged 4-5 years). Child anxiety was assessed in relation to children's performance predictions and evaluations, observed behaviour and self-reported affect. Mothers were trained to vary their behaviour on the basis of both verbal instructions and a training video which focused specifically on parental control behaviours. Observed maternal behaviours were coded for both levels of control and negativity, to ensure that effects found were specifically associated with 
differences in parental control. A measure of pre-existing child anxiety was also obtained in order to assess potential moderating effects, as children may be deemed to be temperamentally sensitive to parenting behaviour on the basis of pre-existing anxious behaviours (e.g. de Rosnay et al, 2006) Finally, a possible problem with experimental methods that involve manipulating parental behaviour is that children's responses may be driven by their parent behaving in a different manner from normal. In order to address this, habitual levels of maternal control were assessed and their moderating influence examined. In summary, we hypothesised that when mothers engage in more controlling (and less autonomy granting) behaviours, children will display increased anxiety in a novel, mildly stressful task (delivering a speech), and this will be moderated by child trait anxiety. We also hypothesized that the effects would not be accounted for by differences in maternal negativity or by differences from mothers' usual level of parental control.

\section{METHOD}

\section{Participants}

The sample consisted of 24 non-clinical children (10 males and 14 females) and their mothers. All children were aged between 4 and 5 years. Participants were recruited through letters sent to parents via nurseries, primary schools and by word of mouth. The inclusion criteria for the study required that both mother and child were fluent English speakers and did not have a learning disability. The majority of the children were classified as being 'White-British' (87\%), were from a two-parent household (87\%) and from families where the occupation of the main household earner was classified as 
'Higher Professional' (in accordance with The National Statistics Socio-economic Classifications, 2005) (87\%).

The study used a Latin-square experimental design in which children experienced both conditions; i) their mothers engaging in controlling parenting behaviours, and ii) their mothers engaging in autonomy-granting behaviours. The order of each condition was counter-balanced in order to eliminate possible order effects (12 children experienced their mothers being controlling first (group A) and 12 children experienced their mothers being autonomy granting first (group B)). In order to minimise the likelihood of the topic creating differences, a social theme was chosen for both speech tasks in order to make them as qualitatively similar as possible. All children spoke about their family in the first condition and spoke about a fun day out in the second condition.

\section{Measures}

Overprotection Scale (Edwards, 2007)

The Overprotection Scale was used to measure mothers' self-reported overprotective/ controlling behaviours in situations which may pose a threat to their child. The scale consists of 19 items, drawn from existing measures of parental control, for example 'I try to anticipate and avoid situations where my child might do something risky', 'I protect my child from his/her fears', 'I accompany my child on all outings'. Parents are required to indicate to what extent they believe each behaviour applies to their parenting practices ('not at all', 'sometimes', 'often', 'very much'). The Overprotection Scale has been 
shown to have good reliability and validity for children aged 3-5 years and to correlate significantly with independent ratings of observed maternal behaviour (Edwards, 2007).

Anxiety Related Behaviours Questionnaire (ARBQ, Eley et al., 2003)

The ARBQ was used to measure trait anxiety in the children. The ARBQ is a 14 item parent report questionnaire. Example items include 'Is often extremely upset or distressed when parent leaves', 'Takes a long time to warm to strangers', 'Tends to be shy or timid'. Parents were asked to indicate whether each item were true of their child ('not true', 'sometimes true', 'certainly true'). It is one of the few questionnaires that assess anxious behaviour in children as young as four years old and has been shown to have good internal consistency (Wheatcroft \& Creswell, 2007).

Observational coding schemes

Children's speeches and mother-child interactions were observed by an independent rater; a trainee clinical psychologist. The videos of the children's speeches were presented independently of the mother-child interactions and were rated for (i) child anxiety during the speech, (ii) parental control vs. autonomy granting, and (ii) parental negativity using clearly defined scales (see below). For reliability purposes, a second rater (graduate psychologist) watched and coded videos of both child speeches and mother-child interactions (again, presented independently of one another) until 100\% consensus was reached $(\mathrm{n}=5)$. A further eleven $(23 \%)$ videos were watched and coded independently in order to assess inter-rater reliability. Both raters were blind to 
experimental condition and were given minimal background information regarding the study.

\section{Child Anxiety}

To assess the level of child anxiety during the speech task, a coding scheme was developed to measure children's display of a range of behaviours associated with inhibition and anxiety (e.g. Did the child attempt to hide their face during their talk?, Did the child fidget excessively during their talk?, Did the child look to their parent for help?, Did the child remain facing the camera?). The items were derived from descriptions of 'behavioural inhibition' (Kagan, Reznick, Snidman, Gibbons \& Johnson, 1988) and clinical observations of anxious children (Hudson \& Rapee, 2001). From an original pool of 21 codes, 12 items were selected to optimize inter-item reliability $(\alpha=0.76)$. Interrater reliability was high $(\mathrm{ICC}=0.98)$.

\section{Parental control vs autonomy granting}

Mothers were rated according to whether they engaged in a series of 12 autonomygranting and controlling behaviours, as shown on the maternal behaviours training video, e.g. 'parent allowed child to generate their own ideas', 'parent encouraged child to try on their own', 'parent spoke/drew/wrote on the paper'. A total score for frequency of behaviours exhibited was calculated (higher score $=$ more controlling, less autonomy granting behaviours). Independent raters showed absolute agreement (ICC $=1.0$ ). 


\section{Parental negativity vs warmth}

In order to control for levels of parental negativity, an additional scale was developed to assess the extent to which the mothers engaged in negative gestures throughout the preparation period. Examples of negative gestures included lack of reciprocity with child, frowning as if to convey dissatisfaction or criticism, laughing inappropriately in the face of child's anxiety or attempts to prepare for the task, verbal or physical behaviours that conveyed disagreement or criticism. Raters assigned an overall score from 0 to 3 to indicate the extent of negative behaviours exhibited during the task. Independent raters showed absolute agreement $(\mathrm{ICC}=1.0)$.

\section{Self-report Measures of Anxiety Related Cognitions and Affect}

Two self-report measures (The Performance Scale and The Feelings Scale) were developed using pictorial ikert scales similar to those used in The Koala Fear Questionnaire (KFQ) (Muris et al., 2003), a psychometrically-robust self-report scale for assessing fears and fearfulness in children.

Two 'Performance Scales' were developed in order to assess each child's estimate of personal coping and resources. The first scale was presented to the child following the preparation period and the child was asked to rate on a five-point Likert scale 'How well do you think you will do in your speech compared to other children?' ('a lot better' to 'a lot worse', 1-5). The second scale was presented to the child after they had completed the talk and asked the child to rate on the same scale 'How well do you think you did compared to other children?'. A 'Feelings Scale' was developed to assess child fearfulness when told about the task and after preparing for the task The researcher asked 
each child to point to how they were feeling on a 5 point scale (where $5=$ 'Very Scared') before and after the mother-child interaction. Children's self report of their feelings significantly correlated with their performance predictions in the expected direction (rho $(21)=.473, \mathrm{p}=0.03)$ giving some indication of the validity of these scales.

Procedure

The experiment was conducted in participants' homes to ensure children were settled and comfortable and in order to avoid anxiety and wariness due to an unfamiliar setting. On arrival a room was organised with a tidy table with chairs for the mother and child. A third chair was set up for the researcher in a corner of the room. A video camera faced the table and chairs and a lap top computer was set up in another corner of the room. Mothers completed the questionnaire measures prior to engaging in the experimental tasks. The children were given brief instructions regarding the conduct of the study and told that they would be asked to talk about 'people in my family' in a little while. They were then asked to indicate how they were feeling about doing their talk (on the 'feelings scale'). The children were given activities to do whilst the mother watched the training video on the laptop computer using a set of headphones. Mothers were randomly allocated to either engage in controlling behaviours first and autonomy-granting behaviours second or vice versa. The video gave instructions on how to behave during the preparation period (either controlling or autonomy-granting, see below). The mothers and children were instructed to spend ten minutes preparing the first talk and this was video-recorded (following Murray et al, 2009). After ten minutes children were asked to indicate how 
they were feeling about doing their talk (on the 'feelings scale') and how they thought they would do compared to other children (the 'performance scale'). The children were then asked to present their talk in front of the camera. If the children had difficulty starting or paused, the researcher used standard prompts to encourage them to keep going. If the children looked distressed or had not spoken for 10 seconds, the researcher praised them and ended the task. All children were stopped after 3 minutes. Children were then asked to indicate how well they thought they had done compared to other children on the 'performance scale'.

The same procedure was followed under the second condition, however during the second administration children were asked to talk about 'a fun day out'. Three children refused to take part in the second speech task (two where mothers had previously been controlling and one where the mother had been autonomy grating).

On completion of both talks, the children were presented with a certificate and given a drawing book as a prize for their efforts. All families were also given a voucher as a token of appreciation.

\section{Maternal Behaviour Training Video}

Four videos were compiled of a female researcher role-playing controlling and autonomy granting interactions during preparation for each of the two speech tasks. The behaviours in the controlling videos were based on clinical descriptions of controlling parents (Barber, 1996; Steinberg, Elmen \& Mounts, 1989) and constructs used in previous 
observational studies to measure parental control (Hudson \& Rapee, 2001). These included: (i) offering frequent guidance and assistance, instruction and direction throughout the task, (ii) drawing and writing on the paper whilst the child was drawing or taking time to think, (iii) sitting close to the child and touching the paper, and (iv) being more involved than appeared necessary. The behaviours in the autonomy-granting videos included (i) allowing the child to come up with their own ideas and complying with these, (ii) sitting back on the chair and only leaning forward when asked to help, (iii) only offering guidance and assistance when asked to, and (iv) encouraging the child to try on his/her own. For both conditions, mothers were given specific instructions on the types of verbal and non-verbal behaviours they should engage in during the preparation period and were shown example interactions demonstrating these. Instructions were displayed on the video screen in addition to a voice-over reading the instructions ${ }^{*}$.

\footnotetext{
${ }^{*}$ Available from the first author
} 


\section{RESULTS}

Data analyses

For Normally distributed data (observed anxious behaviours), the main effect of condition (autonomy granting vs controlling) and interaction with child anxiety (ARBQ) was examined using repeated measures analysis of variance. For the remaining continuous variables (children's predictions prior to the speech, evaluations following the speech, and self-reported scared feelings) data was negatively skewed and did not respond favourably to transformations, therefore main effects were examined using Wilcoxon's signed-rank test. For these variables, interactions were examined by correlating the difference between scores under each of the experimental conditions with child anxiety (ARBQ). Means and standard deviations for all variables in each condition are shown in table one.

Where experimental effects were found it was important to establish that these were not accounted for by (i) mothers interacting with their child in a different way to their usual parenting style, or (ii) changes in another potentially important parenting dimension, i.e. negativity. For children's observed anxious behaviours, maternal overprotection (questionnaire) scores and observed negativity scores were entered in to analyses of variance as a covariate. For non-Normally distributed data, interactions were explored by correlating difference scores between the experimental groups with maternal overprotection and negativity. 


\section{Preliminary analyses}

Observations of parent behaviour indicated that mothers' mean controlling behaviour scores in the controlling condition was significantly higher than in the autonomy-granting condition $(\mathrm{t}(18)=21.93, \mathrm{p}=0.001)$ demonstrating that the experimental manipulation of maternal behaviour was successful. Notably, observed maternal negativity scores were also significantly higher in the controlling condition than in the autonomy-granting condition $(\mathrm{t}(19)=3.94, \mathrm{p}<0.001)$, emphasising the importance of controlling for negativity when testing hypotheses. To confirm that there were no significant order effects, scores for children receiving autonomy granting parenting first were compared to those of children receiving controlling parenting first on all the cognitive, behavioral and affective scales. There were no significant differences on any of these scales (all p's > $.10)$.

Children's observed anxious behaviours

The main effect of experimental condition on independent ratings of observed child anxiety approached significance $(\mathrm{F}(1,16)=3.27, \mathrm{p}=.09)$. There was not a significant main effect of child trait anxiety on observed child anxiety (ARBQ; $F(1,16)=.08, p=.79$ ), however the interaction of condition and child anxiety was significant $(F(1,16)=4.52$, $\mathrm{p}=.05$ ). As shown in Figure 1, in contrast to less anxious children who showed a slight reduction in anxious behaviours in the controlling condition, children with higher levels of trait anxiety evidenced an increase in anxious behaviours in the controlling condition in comparison to the autonomy granting condition. The significant interaction between condition and child trait anxiety was maintained when maternal overprotection 
questionnaire score and difference in observed negativity between conditions were entered as covariates $(\mathrm{F}(1,14)=5.63, \mathrm{p}=.03)$.

Children's self-reported cognitions and affect

Children predicted that they would do less well before giving a speech in the controlling condition compared to the autonomy-granting condition $(\mathrm{z}=-3.13, \mathrm{p}=0.002)$. The difference in pre-speech prediction scores between experimental conditions did not correlate with child trait anxiety $(\mathrm{r}(20)=-.06, \mathrm{p}=.79)$. The experimental effect was also not associated with maternal habitual overprotection $(\mathrm{r}(20)=-.19, \mathrm{p}=.44)$ or the difference in negativity across conditions $\left(\mathrm{r}^{\mathrm{b}}(20)=-.18, \mathrm{p}>.10\right)$.

Children also reported feeling significantly more scared after the preparation period in the controlling condition $(\mathrm{z}=-2.89, \mathrm{p}=0.004)$. Child trait anxiety (ARBQ) was not significantly correlated with the difference score for scared feelings after the preparation period $(\mathrm{r}(20)=-.27, \mathrm{p}=.26)$. The experimental effect for scared feelings after the preparation phase was not accounted for by either habitual maternal overprotection $(\mathrm{rho}(20)=-.05, \mathrm{p}=.84)$ or the difference in maternal negativity between conditions $\left(\mathrm{r}^{\mathrm{b}}\right.$ $(20)=-.19, p>.10)$. Children did not differ in their performance evaluations following the task across experimental conditions $(\mathrm{z}=-.09, \mathrm{p}=0.93)$ and there was no evidence of a moderating effect of child trait anxiety as assessed by the ARBQ $(\operatorname{rho}(20)=.18, p=.45)$. 


\section{DISCUSSION}

Mothers were successfully trained to vary in the degree to which they exhibited controlling or autonomy- granting parenting behaviours whilst their child prepared for a speech task- with significant differences in the degree of autonomy promoting vs. controlling behaviours being observed across the experimental conditions. When children experienced their mothers being more controlling during the preparation period (compared to autonomy-granting behaviors), there was a trend towards more observed child anxiety during the delivery of the speech task. This effect was strengthened (representing a significant interaction) among children who had higher levels of trait anxiety (as assessed by the ARBQ), who displayed significantly more anxious behaviours when their mothers were controlling. Importantly this effect was independent of usual maternal overprotection and observed maternal negativity. Whilst caution must be maintained when interpreting the findings which relied on child self-report, it was found that children also predicted that they would do less well prior to the speech task and also reported feeling significantly less happy and more scared about the task when their mothers were controlling during the preparation period. Again this effect was independent of maternal reported usual overprotection and observed maternal negativity.

These findings contribute to the literature regarding the development of anxiety disorders in children and support the notion that parental control reinforces child anxiety (e.g. Rapee, 2001). Although differences in observed child anxiety during each condition did not reach statistical significance, the majority of the children who took part in the study were confident and were rated by their mothers as showing low levels of trait anxiety 
prior to the study. The coding scheme may have lacked sensitivity to pick up small changes in anxiety as it relied on the expression of clear behavioural indications. As such it is perhaps not surprising that these children were not rated as displaying substantial changes in observable anxiety following a single 10 minute controlling interaction. Chorpita and Barlow (1998) postulated that early experiences of uncontrollability may contribute to the development of anxiety over time. Based on this theory, exposure to multiple experiences of uncontrollability may contribute to the development of increased anxiety. However, in common with previous experimental studies, changes in children's responses after a brief single interaction with their parent were heightened among children who were prone to increased trait anxiety (De Rosnay et al., 2006). This supports the hypothesis that controlling behaviours may have a particularly influential role on children with a pre-existing vulnerability to anxiety (e.g. Murray, Creswell \& Cooper, 2009).

With regards children's self-reported anxious expectations, controlling parenting was associated with a significant reduction in children's confidence before delivering the speech. This is consistent with Rapee's theory that excessive control reduces children's perception of mastery over novel or threatening events (Rapee, 2001). In contrast when children were encouraged to be more independent, they had greater opportunity to experience mastery and had no reason to doubt their competency. Consistent effects were found for child self-reported feelings, i.e. when mothers engaged in controlling behaviours children reported feeling significantly more scared before the speech task. Whether the stronger main effects for these cognitive variables and the lack of significant 
interactions with child trait anxiety, in comparison to observed behaviours, is a result of more direct pathways of transmission or are a result of qualities of the measures used cannot be ascertained from this study,but would be of interest in future work.

Interestingly, differences in parenting behaviours were not associated with significant differences in children's self-evaluations following the speech task. A possible explanation for this is that although controlling parenting may increase levels of self doubt before the task, exposure to successful coping (i.e. completing the speech task independently) could restore and increase the child's confidence in their own ability. All the children completed the task independently following the preparation period and hence had the opportunity to experience mastery. In contrast clinically anxious children might be more inclined to avoid situations in which they fear a negative outcome (e.g. Barrett, Rapee, Dadds \& Ryan, 1996) leading to ongoing negative performance expectations.

Whilst the findings of this study are consistent with theories of the development of anxiety, generalisation to a clinical population is limited by the use of a small nonclinical sample participating in a contrived experimental situation. Extension of this work to naturalistic settings with clinical populations is warranted. In addition, the study was limited to preschool children and their mothers from a predominantly White-British middle-class sample. Both developmental and cultural factors are likely to moderate the influence of parenting behaviours and, as such, future research including children of different ages and cultural backgrounds is required. Equally, the impact of parenting behaviour may vary according to parent gender or their parental role (e.g. Bogels \& 
Phares, 2008) and this needs to be taken into account in future research. The measures of anxiety related cognitions and affect relied on children's self report and the reliability of these, therefore, may be questionable. Children's self report of their feelings significantly correlated with their performance predictions in the expected direction, supporting validity of the measures, however the reliability of these measures requires further evaluation. The inclusion of an objective assessment of child expressed anxiety represents a strength of the study, however may be less sensitive to change associated with the experimental manipulation. The addition of physiological measures of anxiety might provide a more sensitive, objective assessment of changes in fear. Finally, although changes in maternal negativity associated with the experimental manipulation were relatively small and effects were maintained when negativity was controlled for, a specific effect of controlling behaviours cannot be concluded with certainty as mothers may have also varied in different aspects of their parenting behaviour as a result of the experimental manipulation. Further research is needed to explore the overlap and interactions between parenting constructs (such as physical affection, tone of voice or infantilising behaviour) in order to better understand the contribution of specific parenting factors. With these limitations in mind, the current study provides support for the hypothesis that controlling parenting leads to increases in anxiety in children, particularly those with a pre-existing vulnerability. 


\section{ACKNOWLEDGEMENTS}

We would like to thank Sarah Shaw for her help with coding. We are also very grateful to Myra Cooper for her advice and support and Paul Griffiths for his time and support in assisting with the statistical methods. Kerstin Thirlwall conducted this study as part fulfillment of her doctorate in clinical psychology at Oxford University. She is now supported by an MRC training fellowship (G0802326). Cathy Creswell is funded by an MRC Clinician Scientist Fellowship (G0601874). 


\section{REFERENCES}

Barber, K. (1996). Parental Psychological Control: Revisiting a Neglected Construct, Child Development, 67, 3296-3319.

Barrett, P.M., Rapee, R.M., Dadds, M.M., \& Ryan, S.M. (1996). Family enhancement of cognitive style in anxious and aggressive children. Journal of Abnormal Child Psychology, 24, 187-203.

Cartwright-Hatton, S., McNicol, K., \& Doubleday, E. (2006). Anxiety in a neglected population: Prevalence of anxiety disorders in pre-adolescent children, Clinical Psychology Review, 26, 817-833.

Chorpita, B. \& Barlow, D (1998). The development of anxiety: The role of control in early environment, Psychology Bulletin, 124, 3-21.

Cooper, P.J., Fearn, V., Willetts, L, Seabrook, H., \& Parkinson, M. (2006). Affective disorder in the parents of a clinic sample of children with anxiety disorders. Journal of Affective Disorder, 93, 205-212.

De Rosnay, M., Cooper, P. J., Tsigaras, N., \& Murray, L. (2006).Transmission of social anxiety from mother to infant: An experimental study using a social referencing paradigm. Behaviour Research and Therapy, 44(8), 1165-1175.

De Wilde, A. \& Rapee, R.M. (2008). Do controlling matrenal behaviours increase state anxiety in children's responses to social threat? A pilot study. Journal of Behaviour Therapy and Experimental Psychiatry, 39, 526-537.

Edwards, S. L., Rapee, R. M., \& Kennedy, S. (2010). Prediction of anxiety symptoms in preschool-aged children: Examination of maternal and paternal perspectives. Journal of Child Psychology \& Psychiatry, 51(3), 313-321. 
Eley, T., Bolton, D., O’Connor, T., Perrin, S., Smith, P., \& Plomin, R. (2003). A twin study of anxiety-related behaviours in pre-school children. Journal of Child Psychology and Psychiatry, 40, 945-960.

Field, A.H. \& Lawson, J. (2003). Fear information and the development of fears during childhood: effects on implicit fear responses and behavioral avoidance. Behaviour Research and Therapy, 41, 1277- 1293.

Hudson, J. \& Rapee, R (2001). Parent-child interactions and anxiety disorders: An observational study, Behaviour Research and Therapy, 39, 1411-1427.

Kagan, J., Reznick, J., Snidman, N., Gibbons, J. \& Johnson, M. (1988). Childhood derivatives of inhibition and lack of inhibition to the unfamiliar, Child Development, 59, 1580-1589.

Last, C., Perrin. S., Hersen, M., \& Kazdin, A (1992). DSM-III-R anxiety disorders in children: Sociodemographic and clinical characteristics, Journal of the American Academy of Child and Adolescent Psychiatry, 31, 1070-1076.

McCleod, B.D., Wood, J.J., \& Weisz, J.R. (2006). Examining the association between parenting and child anxiety: A meta-analysis. Clinical Psychology Review, 27, 155172.

Murray, L.M., Creswell, C., \& Cooper, P.J. (2009). Anxiety Disorders in Childhood. Psychological Medicine, 39, 1413-1423.

Murray, L., Pella, J., Lau, M., Schofield, E., \& Cooper, P. (2009) Intergenerational transmission of social phobia: maternal meaning making processes, and specificity of effects. Annual conference of the European Association of Behavioural and Cognitive Psychotherapies. 
National Statistics Socio-economic Classification User Manual.(2005). Office for National Statistics.

Ohman, A (1985). Face the beast and fear the face: Animal and social fears as prototypes for evolutionary analysis of emotion, Psychophysiology, 23, 123-145.

Rapee, R (1997). Potential role of childrearing practices in the development of anxiety and depression, Clinical Psychology Review, 17, 47-67.

Rapee, R (2001). The development of generalised anxiety. In M. Vaey, and M. Dadds (eds), The developmental psychopathology of anxiety, (p481-503), New York: Oxford University Press.

Rapee, R., Kennedy, S., Ingram, M., Edwards, S., \& Sweeney, L (2005). Prevention and early intervention of anxiety disorders in inhibited preschool children, Journal of Consulting and Clinical Psychology, 73, 488-497.

Rosenbaum, J., Biederman, J., Bolduc, E., Hirschfeld, D., Faraone, S., \& Kagan, J. (1992). Comorbidity of parental anxiety disorders as risk for childhood onset anxiety in inhibited children, American Journal Psychiatry, 149, 475-581.

Rubin, K., Burgess, K., \& Hastings, P. (2002). Stability and social-behavioural consequences of toddlers' inhibited temperament and parenting behaviours, Child Development, 73, 483-395.

Rubin, K., Cheah, C., \& Fox, N (2001). Emotional regulation, parenting and display of social reticence in preschoolers, Early Education and Development, 12, 97-115.

Silverman, W. \& Ginsburg, G (1998). Anxiety disorders. In M. Hersen, and T. Ollendick (eds) Handbook of child psychopathology (p239-268) New York: Plenum Press.Steinberg, L., Elmen, J. D, \& Mounts, N. S. (1989). Authoritative parenting, 
psychosocial maturity, and academic success among adolescents. Child Development, 60, 1424-1436

Wheatcroft, R. \& Creswell, C. (2007). Parents' cognitions and expectations about their pre-school children: The contribution of parental anxiety and child anxiety, The British Journal of Developmental Psychology, 25, 435-441.

Wood, J., McLeod, B., Sigman, M., Hwang, W., \& Chu, B (2003). Parenting and childhood anxiety: theory, empirical findings, and future directions, Journal of Child Psychology and Psychiatry, 44, 134-151. 
Table one Means, standard deviations and ranges

\section{Experimental condition}

Autonomy granting Controlling
$\mathrm{N}=22$
$\mathrm{N}=23$

$\underline{\text { Pre-interaction }}$

Child self-reported scared

1.80

2.14

feelings

$(1.36,1-5)$

$(1.06,1-4)$

During interaction

Observed maternal control

.68

10.10

$(1.00,0-3)$

(1.97, 4-12)

Observed maternal

0.05

0.45

negativity

$(.22,0-1)$

$(.51,0-1)$

$\underline{\text { Post-interaction }}$

Child self-reported

1.45

2.43

performance predictions

$(.76,1-3)$

$(1.16,1-5)$

Child self-reported scared

1.80

2.57

feelings

$(1.06,1-4)$

$(1.29,1-5)$

During speech task

Observed child anxious

2.55

2.70

behaviours

$(2.45,0-9)$

$(2.32,0-9)$

$\underline{\text { After speech task }}$

Child self-reported

1.70

1.71

performance evaluations

$(.92,1-3)$

$(.46,1-2)$ 
Figure 1 Observed child anxious behaviours: Interaction between experimental condition and child anxiety as measured by the Anxiety Related Behaviours Questionnaire

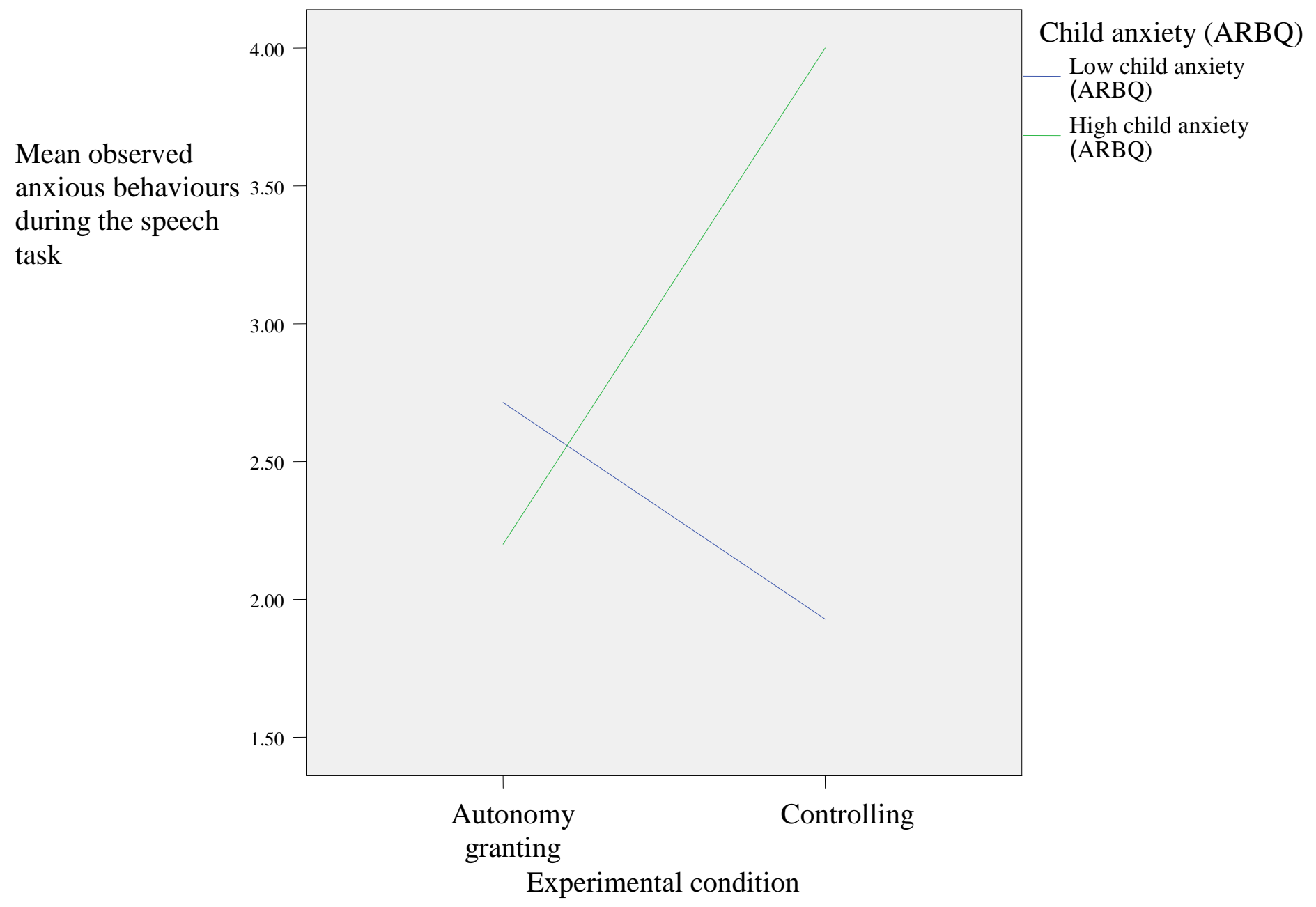

NB. Interaction effects were analysed using continuous ARBQ data, median splits are used in the above figure purely for illustrative purposes. 
